функционировать только с 1999 года, а классические национальные ЦБ существуют уже давно, можно сделать выводы, что, во-первых, ЦБ эволюционировали от классического национального ЦБ до классического наднационального ЦБ, а во-вторых, их развитие и модернизация происходили на базе национального ЦБ.

Список литературы:

1. Ильина Т.Г., Беспалова О.В. Организация деятельности Центрального банка / Учебное пособие под ред. проф. А.А. Земцова. Издательский дом Томского государственного университета. Томск, 2014. - 320 с.

2. Rudolf Bächtold, Peter Kratz, Wolfgang Winter, Peter Haenle. Eine Adresse in Liechtenstein. Finanzdrehscheibe und Steuerparadies. Gabler Verlag. Wiesbaden, 1979. 208s.

3. Ein Kurzporträt. Schweizerische Nationalbank. Generalsekretariat [Электронный pecypc]. 7. Auflage. Juni 2012. Zürich. - 19 s. URL: http://www.vwlonline.ch/makrookonomie/geldtheorie-und-politik/SNB\%20Kurzportrait.pdf

4. Смирнова О.В. Центральные банки зарубежных стран: финансовое состояние и финансовые результаты: монография. - Тверь: Твер. гос. ун-т, 2014. - 108 с.

5. Денежно-кредитная политика ЕЦБ [Электронный ресурс]. 2004. Европейский центральный банк. Франкфурт-на-Майне, 2004. 161 с. -

URL: http://www.ecb.europa.eu/pub/pdf/other/monetarypolicy2004ru.pdf

\title{
Значение Центрального банка и денежно-кредитной политики для общества, государства и мира в 21 веке
}

Беспалова О.В., аспирант, Национальный исследовательский Томский государственный университет, г. Томск E-mail: bespo@yandex.ru

Научный руководитель: к.э.н., доцент Ильина Т.Г.

В настоящий момент в экономической науке малоизучено значение ЦБ и ДКП для общества, государства и мира в 21 веке. Однако это направление исследований очень актуально. Это связано с тем, что понимание значения ЦБ и ДКП позволит направить усилия по их совершенствованию и модернизации именно в том направлении, которое сегодня особенно важно для современного общества, государства и мира.

Мы считаем, что современный ЦБ имеет следующее значение для государства или валютного союза:

1. ЦЦБ - это главное финансовое учреждение с особым статусом и особыми полномочиями. О важной роли и высоком статусе ЦБ как учреждений говорит название ЦБ: например, Национальный банк Австрии, Национальный банк Бельгии, Центральный банк Ирландии, Центральный банк Люксембурга, Банк Франции, Банк Эстонии, Центральный банк Российской Федерации, Европейский центральный банк и т. д. В названии подчёркивается главенствующая роль и принадлежность 
определённому государству. Никакое другое финансовое учреждение в стране или валютном союзе не удостоилось такой чести.

2. ЦБ организует эффективное функционирование государства или валютного союза. Например, ЦБ реализует ДКП, обеспечивает страну достаточной денежной массой, а в случае форс-мажора органы государственной власти надеются на достаточное количество резервных средств и ресурсов у ЦБ для преодоления кризиса.

3. ЦБ способствует поддержанию порядка в экономической сфере государства или на территории группы стран (например, за счёт выполнения надзорной и контролирующей функций).

4. ЦБ дисциплинирует государство. Например, ориентация ЦБ на выполнение определённых экономических целей, в том числе целей ДКП, может заставить государство пересмотреть и другие ориентиры для достижения общего соответствия политике и курсу ЦБ.

Значение ЦБ для общества, по нашему мнению, заключается в следующем:

1. ЦБ организует, гарантирует и обеспечивает жизнь общества внутри государства или валютного союза.

2. ЦБ удовлетворяет основные потребности общества, например, желание проживать жизнь, создавать и приумножать сбережения, покупать товары и услуги.

3. ЦБ удовлетворяет право общества на благополучную жизнь (право на достойную жизнь и обеспеченную пенсию, право на получение необходимого образования и качественную медицинскую помощь, право на отдых за счёт элементарного обеспечения экономики деньгами и регулирования денежно-кредитных отношений, то есть за счёт создания финансовой основы и экономических условий для жизни).

4. ЦБ обеспечивает финансовую защиту общества и поддерживает его уверенность «в завтрашнем дне». В свою очередь это выражается, например, в том, что:

a) общество надеется на то, что национальная валюта будет стабильна и не обесценится, а, значит, граждане смогут уверенно создавать и накапливать сбережения;

b) общество надеется на эффективное функционирование банковской системы, например, на то, что банки установят выгодные ставки по депозитам и население сможет увеличивать свои сбережения;

с) общество надеется на то, что ЦБ будут добросовестно осуществлять надзор и контроль за банковской системой, и это исключит своеволие и мошенничество в этой сфере, например, обман населения кредитными учреждениями;

d) общество надеется, что ЦБ вовремя предотвратят инфляцию или повлияют на её уровень с помощью ДКП или других мер;

е) общество надеется, что национальная валюта будет иметь высокий статус и высоко котироваться в мировой экономике;

f) общество доверяет ЦБ в том, что не будет бесконтрольной выдачи лицензий коммерческим банкам, ЦБ будет должным образом проверять данные, предоставляемые банками для их регистрации, а в случае необходимости ЦБ своевременно и обоснованно приостановит их деятельность;

g) общество ожидает от ЦБ профессионализма, ответственности, справедливости, логичности действий и полной максимально возможной транспарентности его деятельности.

Экономики стран взаимодействуют между собой, поэтому очень важна слаженная работа абсолютно всех ЦБ мира в направлении достижения общего 
благополучия и повышения уровня и качества жизни населения. На наш взгляд, синхронность деятельности ЦБ мира для достижения этих целей может достигаться с помощью следующих действий:

1. ЦБ могли бы гипотетически учредить коалицию ЦБ мира (возможно, таким образом эта коалиция могла бы, например, устанавливать единые стратегические экономические цели на краткосрочную, среднесрочную и долгосрочную перспективы, контролировать их выполнение и содействовать их выполнению, а также, возможно, оказывать влияние на политический курс стран).

2. Сильные ЦБ могут поддерживать слабые ЦБ, например, информационно (предоставлять статистические данные, переводы отчётов о своей деятельности, различные комментарии по поводу своих действий и другие сведения, не являющиеся банковской тайной).

3. ЦБ могут обмениваться опытом осуществления своей деятельности (например, опытом проведения ДКР или ДКП). Коалиция ЦБ могла бы также организовать стажировки сотрудников одних ЦБ в других ЦБ для обмена профессиональным опытом.

4. ЦБ могут организовывать международные встречи, конференции, симпозиумы и форумы.

5. ЦБ могут организовывать заседания и встречи президентов и представителей ЦБ всех стран мира на международном уровне.

6. ЦБ (например, коалиция ЦБ) могут совместно разработать единые мировые стандарты содержания организации деятельности национальных и наднациональных ЦБ, единые мировые стандарты проведения ДКП и осуществления ДКР, единые мировые стандарты противодействия легализации доходов, полученных преступным путём, единые мировые стандарты для коммерческих банков и т. д.

7. ЦБ (например, коалиция ЦБ) могли бы разработать единые мероприятия и рекомендации для борьбы с инфляцией и преодоления финансовых кризисов.

8. Коалиция ЦБ могла бы создать единую мировую платёжную систему (это было бы полезно, например, для вытягивания бедных стран до уровня и стандартов европейских стран).

9. Коалиция ЦБ могла бы разработать единые стандарты и параметры финансовой стабильности стран.

10. Коалиция ЦБ могла бы разработать и установить единые мировые требования к руководству ЦБ (образование, опыт работы, опыт работы на руководящих должностях и т. д.).

11. ЦБ (например, коалиция ЦБ) могли бы организовать Международный институт повышения квалификации для сотрудников ЦБ мира или другое аналогичное учреждение, различные курсы для достижения этой цели, разрабатывать обучающие дистанционные программы на международном уровне.

12. Коалиция ЦБ могла бы решать и другие вопросы, например, заниматься благотворительностью или оказывать разовую финансовую помощь бедным странам, финансово поддерживать науку, образование, экологические и другие проекты в разных странах.

Кроме того, деятельность одних ЦБ может становиться примером для других ЦБ, что также способствует повышению мирового экономического уровня. Например, по мнению С. Р. Моисеева, существует вероятность, что ЦБ США (по опыту ЕЦБ) 
также в итоге станет ориентироваться на ценовую стабильность, как конечную цель ДКП [1, стр. 40].

Таким образом, значение современных ЦБ в 21 веке для мира видится нам в тесном сотрудничестве и взаимодействии ЦБ между собой с целью достижения единых целей для всех стран, а именно, экономической стабильности, экономического роста, повышения уровня и качества жизни. Спорными при этом являются следующие вопросы, требующие всестороннего рассмотрения:

1. По какому принципу должно строиться сотрудничество ЦБ мира (например, каким образом руководство коалиции ЦБ будет принимать решение о принятии ЦБ разных стран в эту коалицию, должно ли такое решение быть принято только руководящим органом коалиции или на основании большинства голосов всех присутствующих представителей ЦБ, каким образом будет происходить сотрудничество между представителями ЦБ стран с развитой экономикой и представителями ЦБ «бедных» стран с низким уровнем жизни и т. д.).

2. Насколько разумно сотрудничество всех ЦБ мира для достижения общей цели перевода человечества на новый более высокий и более благополучный уровень жизни (ведь существует разница менталитетов, между некоторыми странами существует огромная пропасть в экономическом развитии).

3. Кто возьмётся за разработку всего содержания деятельности такой коалиции (например, устава, всей документации, правил, принципов созыва её членов и т. д.). Должны ли это сделать, например, специальная комиссия или совет, созданные из представителей ЦБ стран с высоким уровнем жизни.

На наш взгляд, значение ДКП для государства заключается в следующем:

1. ДКП является регулятором репутации ЦБ в глазах общества и регулятором доверия общества к ЦБ. Без доверия населения к ЦБ невозможно будет нормально управлять страной и развивать экономику.

2. ДКП является регулятором репутации ЦБ в мире и регулятором доверия других государств к ЦБ и стране, в которой этот ЦБ функционирует. Без этого доверия будет трудно налаживать международные взаимоотношения.

3. ДКП - «двигатель» экономики государства в требуемое русло в соответствии с его потребностями.

4. ДКП должна стать «щитом» государства в борьбе с экономическими кризисами и его последствиями.

Для общества значение ДКП заключается в следующем:

1. ДКП должна в полной мере и даже сверх меры удовлетворять право граждан на жизнь в экономически развитом, стабильном государстве, в котором интенсивно и гармонично развиваются все сферы экономики и неэкономические сферы общественной жизни. Сверх меры, так как после тяжёлых и кровопролитных событий начала 20 века (первая и вторая мировые войны, сталинские репрессии, геноцид нации в России), а также в связи с общей нестабильностью в мире (например, проблемы с мигрантами в европейских странах в 2016 году, гражданские войны на Украине, в Сирии, Сомали, Ливии, на Синайском полуострове в 21 веке), современными техногенными и экологическими катастрофами общества заслуживают спокойную и благоустроенную жизнь в процветающих государствах.

2. ДКП должна быть одним из центральных способов повышения уровня и качества жизни населения. 
Мы считаем, что значение ДКП для мира в 21 веке заключается в том, что она за счёт общих усилий и сотрудничества стран и ЦБ мира должна стать способом повышения качества и уровня жизни во всём мире (например, за счёт разработки ЦБ единых мировых стандартов содержания ДКП).

На основании всего вышеизложенного можно сделать вывод, что современным ЦБ и ДКП отводится одна из главных ролей в экономике государств и валютных союзов, жизни общества, мировой экономике и человечестве на современном этапе его развития в целом. Наше исследование этого вопроса не закончено, мы продолжим изучать данную проблему в наших следующих научных работах. Мы считаем, что для перехода современной человеческой цивилизации на следующий, новый, более совершенный, более благополучный этап развития следует тщательно рассмотреть проблему значения современных ЦБ и ДКП для экономики и повышения качества и уровня жизни, и внести соответствующие изменения в содержание организации деятельности современных ЦБ и содержание ДКП в соответствии с потребностями общества. Скорее всего, в ближайшие годы и десятилетия государства не откажутся от ЦБ и не придумают ничего нового для регулирования экономики, а те страны (как правило, развивающиеся с низким уровнем жизни), в которых до сих пор вследствие различных причин отсутствовали ЦБ, придут к необходимости учреждения ЦБ. Сегодня современные ЦБ и ДКП несовершенны, существует масса направлений в деятельности ЦБ, требующих доработки или изменений. Во многих странах (например, в России, на Украине) ЦБ должны срочно разработать и реализовать комплекс радикальных мер для повышения уровня и качества жизни населения (хотя бы до уровня жизни европейских стран). Если ЦБ этого не сделают, то население стран с низким уровнем жизни (к которым мы относим и Россию) в лучшем случае на некоторое время останется с современными доходами и современными возможностями потребления, а в худшем случае - в ближайшие годы начнёт беднеть. Для создания такого комплекса радикальных мер необходимо понимание значения современных ЦБ и ДКП для общества, государства и мира в 21 веке.

\section{Список литературы:}

1. Моисеев С.Р. Зачем нужен центральный банк // Банковское дело. 2008. № 8. C. $40-46$ 